\title{
Knowledge Level of Recommended Jute Production Technology among Growers in Kosi Region of Bihar
}

\author{
Amit Kumar ${ }^{1}$, M. N. Ansari ${ }^{2 *}$ and Ashok K. Singh ${ }^{3}$ \\ Department of Extension Education, Dr. Rajendra Prasad Central Agricultural University, \\ Pusa, Samastipur, India \\ *Corresponding author
}

\section{A B S T R A C T}

\begin{tabular}{|l|}
\hline Key w o r d s \\
Knowledge level, \\
Production \\
technology, \\
Jute growers \\
\hline Article Info \\
$\begin{array}{l}\text { Accepted: } \\
\text { 07 October } 2020 \\
\text { Available Online: } \\
10 \text { November } 2020\end{array}$ \\
\hline
\end{tabular}

Keywords

Knowledge level, Production technology, Article Info

Accepted: Available Online: 10 November 2020

\begin{abstract}
The study was carried out in Kosi region of Bihar. The findings indicated that the maximum numbers of respondents were having medium level (61.11 per cent) of knowledge regarding jute production technology respectively. The results of practice wise knowledge level of jute growers about jute cultivation practices clearly indicated that majority of the growers have knowledge about method of extraction (83.33\%), method of application of fertilizer $(61.11 \%)$, time of harvesting $(61.11 \%)$, but lowest knowledge in case of method of application of pesticides $(27.77 \%)$, quantity of application of pesticides (22.22\%), seed treatment methods (16.66\%), time of application of insecticides (16.66\%) and use of chemical and micro nutrients $(5.55 \%)$. The study also revealed that out of ten independent variables, eight variables i.e. education, land holding, annual income, extension contact, mass media exposure, scientific orientation, economic orientation and risk orientation shows positive significant relationship with the knowledge level of jute growers towards jute cultivation practices.
\end{abstract}

\section{Introduction}

Jute (Corchorus olitorius and C. capsularis) is regarded as India's golden fiber and plays an important role in country's economy. It is an important cash crop and contributes to the farm income of a large section of rural households. It is predominantly grown by farmers of Eastern India mainly West Bengal, Odisha, Bihar, Assam and Uttar Pradesh. Jute requires a warm and humid climate and can be grown within a temperature range of $24^{\circ} \mathrm{C}$ to $37^{\circ} \mathrm{C}$ and a relative humidity of 57 to $97 \%$. Jute crop thrives well with alternate rains and sunshine. It is the commercially available natural fiber which is utilized mostly as packaging material. Jute is eco-friendly, biodegradable and has much higher $\mathrm{CO}_{2}$ assimilation rate which is creating an opportunity for the survival and growth of jute industry in the era of environmental concern. It is evident that cultivation of jute generates huge employment in the rural and urban areas.

India is the largest producer of raw jute. Although productivity of jute in India is higher than world average but substantial 
yield gap exists between potential yield under frontline demonstration and actual yield at farm level. As per Directorate of Jute Development estimates, yield gap varies from about 24 percent in West Bengal to 62.4 percent in Bihar. The yield gap needs to be narrowed down and jute yield can be increased by adopting better management practices and using quality high yielding seeds. Another issue in jute production is quality of jute fibre produced in the country despite significant progress in research in jute sector.

The share of superior grade jute varieties has remained almost constant during the last two decades. Jute Corporation of India has undertaken a project ICARE for jute with an aim to enhancing productivity and quality of raw jute with provision for supplying new variety of jute seeds at subsidized rates, introduces better agronomic practices and recently developed microbial assisted retting technique among farmers.

In Bihar, the major drawback related with jute production technology may be the lack of knowledge of recommended package of practices, lack of awareness among the farmers and their socio-economic characters which might have got some effects on adoption of improved practices in jute cultivation. Therefore, it is desirable to make them aware of recommended practices of jute cultivation and to increase the knowledge level, which in turn facilitates higher adoption of jute packages and practices. With this view, the study has been undertaken to measure the level of knowledge of growers related with recommended jute production technology.

\section{Materials and Methods}

The study was carried out in Kosi region of Bihar in view of its importance in major jute growing belts of the state. Three district namely Madhepura, Saharsa and Supaul were selected for the study, from these three districts one block from each district were selected on the basis of major area under jute cultivation.

And from each block two villages were selected randomly, further fifteen respondents were selected from each village constituting a total sample size of 90 jute growers for the study purposes. Face to face interaction with the help of well prepared interview schedule was used for collection of information. The collected data were analyzed with the help of frequency distribution, mean, standard deviation and Pearson's correlation coefficient.

\section{Results and Discussion}

\section{Knowledge level of jute growers about recommended jute production technology}

Knowledge can be operationalised as an awareness or understanding of something or refer to a theoretical or practical understanding of a subject. The information pertaining to the overall level of knowledge regarding jute cultivation practices were classified into three categories like low, medium and high according to their correct responses given at the time of interview.

From the table 1 , it is observed that the most of the respondents $(61.11 \%)$ were having medium level of knowledge regarding jute production technology where as 20.00 and 18.89 percent of the respondent were having low and high level of knowledge regarding jute production technology respectively. This finding is in conformity with the findings acquired by the researcher Reddy (2003), Chikkana et al., (2005) and Madiajagan and Somasundaram (2002). 
Table.1 Distribution of jute growers according to their overall knowledge level

\begin{tabular}{|c|c|c|c|}
\hline SI.No. & Category & Frequency & Percentage \\
\hline $\mathbf{1}$ & Low $(<47.87)$ & 18 & 20.00 \\
\hline $\mathbf{2}$ & Medium $(47.87-81.27)$ & 55 & 61.11 \\
\hline $\mathbf{3}$ & High $(>81.27)$ & 17 & 18.89 \\
\hline
\end{tabular}

Table.2 Extent of knowledge of jute growers regarding improved package and practices for jute cultivation

\begin{tabular}{|c|c|c|c|c|}
\hline \multicolumn{2}{|c|}{ Sl. No. } & Practices & Frequency & Percentage \\
\hline \multirow[t]{4}{*}{1.} & \multicolumn{4}{|c|}{ Field preparation } \\
\hline & a. & No. of ploughing & 48 & 53.33 \\
\hline & b. & Time of ploughing & 45 & 50.00 \\
\hline & c. & Leveling & 30 & 33.33 \\
\hline \multirow[t]{8}{*}{2.} & & Seed and sowing & & \\
\hline & a. & Improved varieties & 50 & 55.55 \\
\hline & b. & Optimum seed rate & 45 & 50.00 \\
\hline & c. & Seed treatment methods & 15 & 16.66 \\
\hline & d. & Right time of sowing & 40 & 44.44 \\
\hline & e. & Method of sowing & 50 & 55.55 \\
\hline & $\mathrm{f}$ & Line sowing & 0 & 0 \\
\hline & $\mathrm{g}$ & Broadcasting & 50 & 55.55 \\
\hline \multirow[t]{6}{*}{3.} & \multicolumn{4}{|c|}{ Manure and chemical fertilizer } \\
\hline & a. & FYM/ compost & 25 & 27.77 \\
\hline & b. & Recommended fertilizer dose & 48 & 53.33 \\
\hline & c. & Use of micro nutrients & 5 & 5.55 \\
\hline & d. & Method of application of fertilizer & 55 & 61.11 \\
\hline & & Time of application & 45 & 50.00 \\
\hline \multirow[t]{4}{*}{4.} & \multicolumn{4}{|c|}{ Irrigation management } \\
\hline & a. & Time of irrigation & 45 & 50.00 \\
\hline & b. & Method of irrigation & 40 & 44.44 \\
\hline & c. & Number of irrigation & 50 & 55.55 \\
\hline \multirow[t]{4}{*}{5.} & & Weed management & & \\
\hline & a. & Time of weeding & 45 & 50.00 \\
\hline & & Method of weeding & 50 & 55.55 \\
\hline & & Weedicides used & 35 & 38.88 \\
\hline \multirow[t]{5}{*}{6.} & \multicolumn{4}{|c|}{ Pest and disease management } \\
\hline & a. & Use of insecticides & 40 & 44.44 \\
\hline & b. & Method of application & 25 & 27.77 \\
\hline & c. & Time of application & 15 & 16.66 \\
\hline & & Quantity of application & 20 & 22.22 \\
\hline \multirow[t]{5}{*}{7.} & \multicolumn{4}{|c|}{ Harvesting and Retting } \\
\hline & a. & Right time of harvesting & 55 & 61.11 \\
\hline & & Method of harvesting & 53 & 58.88 \\
\hline & & Duration of retting & 40 & 44.44 \\
\hline & & Method of extraction & 75 & 83.33 \\
\hline \multirow[t]{3}{*}{8.} & \multicolumn{4}{|c|}{ Marketing } \\
\hline & & When to sell & 45 & 50.00 \\
\hline & & Where to sell & 55 & 61.11 \\
\hline
\end{tabular}


Table.3 Relationship between selected independent variables with knowledge about jute production technology

\begin{tabular}{|l|l|c|}
\hline SI.No. & Independent Variables & 'r' value \\
\hline $\mathbf{1 .}$ & Age & $-0.243^{*}$ \\
\hline $\mathbf{2 .}$ & Education & $0.556^{* *}$ \\
\hline $\mathbf{3 .}$ & Caste & $0.015 \mathrm{NS}$ \\
\hline $\mathbf{4 .}$ & Land holding & $0.725^{* *}$ \\
\hline $\mathbf{5 .}$ & Annual income & $0.776^{* *}$ \\
\hline $\mathbf{6 .}$ & Extension contact & $0.623 * *$ \\
\hline $\mathbf{7 .}$ & Mass media exposure & $0.648^{* *}$ \\
\hline $\mathbf{8 .}$ & Scientific orientation & $0.377^{*}$ \\
\hline $\mathbf{9 .}$ & Economic orientation & $0.394 *$ \\
\hline $\mathbf{1 0}$ & Risk orientation & $0.513 * *$ \\
\hline * Significant at 0.05 level of probability ** Significant at 0.01 level of probability
\end{tabular}

\section{Practice wise Knowledge level of jute growers}

It can be seen from Table 2 that the knowledge level of jute growers in different component wise jute production technology were, in terms of field preparation the majority of the farmers have knowledge about time and number of ploughing in jute cultivation. In terms of manure and chemical fertilizer, the majority of the farmers have knowledge about fertilizer dose, method of application and time of application of fertilizer. The majority of the farmers have knowledge about method of weeding because they generally manual weeding is done in their field but they have lower knowledge about weedicides and time of application in terms of weed management. In terms of harvesting and retting, the majority of the farmers have knowledge about time of harvesting, method of harvesting, method of extraction of jute fibers but they have less knowledge about duration of retting so they are not able to produce fine and strong quality of jute fibers. In terms of marketing, majority of the farmers have knowledge about when and where to sell because they always sell to local retailer they informed the farmers about market price.
Association between selected independent variables with knowledge regarding jute production technology

The knowledge about jute production technology is affected by various socioeconomic and personal characteristics as well as demographic attributes. The attempt has been made to explore the relationship between selected independent variables with knowledge about jute production technology. The zero order correlation was computed to know the relationship between knowledge and selected independent variables such as age, education, caste, size of land holding, annual income, extension contact, mass media exposure, scientific orientation, economic orientation, and risk orientation. The results are present in the table 3 .

It was evident from the table that the computed value of ' $r$ ' the education, land holding, annual income, extension contact, mass media exposure, scientific orientation, economic orientation, risk orientation are significant at 0.01 level of probability and the other variables such as age is negatively significant correlation with the knowledge of jute production technology at 0.01 level of probability. Caste is no significant 
relationship with the knowledge about jute cultivation practices. This result was in conformity with the Benal et al., (2010), Sagwal and Malik (2001) and Saha et al., (2012).

From the findings of the study it could be concluded that most of jute growers were having medium level of knowledge regarding jute production technology. In case of practice wise knowledge level, majority of the growers have knowledge about method of extraction $(83.33 \%)$, but lowest knowledge in case of use of chemical and micro nutrients $(5.55 \%)$. Hence, effort should be made to increase the knowledge for use of chemical and micronutrients. The study also indicated that variables i.e. education, land holding, annual income, extension contact, mass media exposure, scientific orientation, economic orientation and risk orientation shows positive significant relationship with the knowledge level of jute growers towards jute cultivation practices. These attributes need to pay more attention by the planners, administrators and extension functionaries while formulating the policy for development.

\section{References}

Benal D, Patel M., Jain MP and Singh VB. (2010). Adoption of Dryland Technology. Indian Journal of Dryland Agriculture Research\&
Development, 25(1): 111-116.

Chikkana, D.M. (2005). Study on adoption behaviour of sericulturists and their characteristics in Kolar district of Karnataka. Indian Jr. Sericulture, 34(1): 10-13.

Kumar R, Ansari M.N, Kumar M. and Kumar N. (2017). Effect of Knowledge level of farmers and Technology recommendation on papaya production in Begusarai district of Bihar.Int.J.Pure App.Biosci.5(6):10321036.

Madiajagan, M and Somasundaram, S. (2002) Cotton farmers field school - An empirical analysis. Journal of Extension Education 13 (2): 33143317.

Reddy, R. S. (2003). A study on knowledge and farming performance of tomato farmers in Chittoor district of Andhra Pradesh. Unpub. M.Sc. (Ag.) Thesis, Andhra Pradesh Agricultural University, Hyderabad.

Sagwal, R.C. and Malik, R.S.(2001). Knowledge index of rice grower farmers. Agril. Extn. Review, pp. 1318.

Saha, B. (2012), Factors influencing adoption of improved production practices of carp in Tripura. Journal of Interacademicia, 16(4): 958-963.

\section{How to cite this article:}

Amit Kumar, M. N. Ansari and Ashok K. Singh 2020. Knowledge Level of Recommended Jute Production Technology among Growers in Kosi Region of Bihar. Int.J.Curr.Microbiol.App.Sci. 9(11): 821-825. doi: https://doi.org/10.20546/ijcmas.2020.911.099 